\title{
The phenolic, 3,4-dihydroxybenzoic acid, is an endogenous regulator of rooting in Protea cynaroides
}

\section{H. C. Wu ${ }^{1}$, E. S. du Toit ${ }^{1}$, C. F. Reinhardt ${ }^{1}$, A. M. Rimando ${ }^{2}$, F. van der $\operatorname{Kooy}^{3}$ and}

J. J. M. Meyer $^{3}$

1. Department of Plant Production and Soil Science, Faculty of Natural and Agricultural Sciences, University of Pretoria, Pretoria, 0002, South Africa

2. Natural Products Utilization Research Unit, ARS, USDA, USA

3. Department of Botany, Faculty of Natural and Agricultural Sciences, University of Pretoria, Pretoria, 0002, South Africa

\begin{abstract}
Analysis of stem extracts identified large quantities of 3,4-dihydroxybenzoic acid and other similar phenolics. The exogenous application of 3,4-dihydroxybenzoic acid on Protea cynaroides explants in vitro significantly increased the root mass at $100 \mathrm{mg} \mathrm{l}^{-1}$, but not at lower concentrations, while root inhibition was observed at $500 \mathrm{mg}^{-1}$. HPLC analysis of cuttings during vegetative propagation showed a considerable increase in 3,4dihydroxybenzoic acid levels from initial planting to when root formation took place, indicating for the first time that 3,4-dihydroxybenzoic acid may be an important phenolic compound in regulating root formation in P. cynaroides cuttings. HPLC analysis also identified caffeic, ferulic, gallic and salicylic acids in the cuttings.
\end{abstract}

\section{Introduction}

Quantification of total phenols in cuttings of Protea cynaroides showed that the total phenol levels increased during root formation (Wu 2006). In addition, the results showed that rooting took place when the total phenol content increased to more than three times the original level in the cuttings. Although very few studies have analyzed the phenolic 
contents of commercially important proteas, several phenolic compounds have been extracted and identified from Protea rubropilosa (Perold et al. 1973), Protea obtusifolia, Protea eximia and Protea neriifolia (Verotta et al. 1999). However, no research has been done on the effects of phenolic compounds on the rooting of proteas.

Phenolic compounds such as caffeic acid, ferulic acid, protocatechuic acid, $p$ hydrobenzoic acid and vanillic acid have all been identified as potential allelopathic agents (Einhellig 2004). Dose-response data often show, depending on the concentration, both inhibitory and stimulatory effects on root growth of test species. The range of concentrations that causes root stimulation is usually narrow, and at lower levels, while root inhibition is effected at higher concentrations.

In addition to the role phenolic compounds play in allelopathy, they have also been identified as endogenous promoters and inhibitors of adventitious rooting. Their effects on the rooting of cuttings have been studied in numerous species, particularly in difficultto-root plants. Various studies on this subject suggest that difficult-to-root stem cuttings tend to contain higher amounts of endogenous rooting inhibitors, which inhibit or delay root formation, compared to easy-to-root stems which have high content of rooting promoters (Fadl and Hartmann 1967; Richards 1964; Taylor and Odom 1970; Biran and Halevy 1973; Reuveni and Adato 1974). Furthermore, a number of phenolic compounds such as catechol (Hackett 1970), chlorogenic acid (Hammerschlag 1982), phloroglucinol (James and Thurbon 1981; Zimmerman 1984) and phloretic acid (Jones and Hatfield 1976) have been used to stimulate root formation, while rutin and tannic acid (Still et al. 1976) have been shown to inhibit root formation in cuttings.

The poor rooting of protea cuttings has often been linked to them being hardwood plants, and therefore, inherently difficult to root. However, as mentioned above, because phenolics have been found to be important in the rooting of numerous plant species, it is likely that phenolic compounds may indeed play a significant role as endogenous rooting regulators in P. cynaroides. The main objective of this study was to determine whether phenolic compounds found in P. cynaroides stems are the causal factors of rooting 
inhibition and/or stimulation. The growth regulating effects of aqueous stem extracts from $P$. cynaroides was assessed on lettuce seeds in a dose-response bioassay. Chemical analysis of compounds in stem extracts was performed in order to establish the identity of phenolic compounds, and to determine if and to what extent they may contribute to rooting inhibition and/or stimulation during in vitro and in vivo propagation.

\section{Materials and methods}

\section{Collection of plant material}

Plant material was obtained from P. cynaroides motherplants grown in an open field near Cullinan, in the Highveld region (summer rainfall) of South Africa. One-year-old semihardwood stems from the current season's growth, which were suitable to be used as cuttings, were removed from the motherplants and used for the bioassay studies, phenolic compound analyses and in vivo propagation.

\section{Lettuce seed bioassay of stem extract}

A dilution series of crude aqueous stem extract was prepared by soaking pieces (approximately $1 \mathrm{~g}$ each) of $P$. cynaroides stems in 1-1 of distilled water for $24 \mathrm{~h}$ in the dark at room temperature. Ten lettuce (Lactuca sativa) cv. 'Great Lakes' seeds were evenly spread on filter paper (Whatman No. 1) lining 9-cm Petri dishes. Five $\mathrm{ml}$ of the stem extracts, ranging from 200 to $5000 \mathrm{mg} \mathrm{l}^{-1}$, were added to each Petri dish. Distilled water was used as the control. Each extract solution was replicated five times. After sealing the Petri dishes with Parafilm ${ }^{\circledR}$ to prevent moisture loss, they were placed in a growth chamber. The temperature of the growth chamber was $25 \pm 2^{\circ} \mathrm{C}$. Cool, white fluorescent lamps provided $60 \mu \mathrm{mol} \mathrm{m} \mathrm{m}^{-2} \mathrm{~s}^{-1} \mathrm{PAR}$ with a 12-h photoperiod. After 6 days, the root lengths of germinated seedlings were measured and the mean root length from each treatment was calculated. A dose-response curve was drawn using the Curve-Fitting to Allelochemical Response Data (CARD) program (Liu et al. 2003).

\section{Osmotic interference}

The determination of osmotic potential of the extracts was done to exclude the possibility of osmotic inhibition in the bioassay, and to ensure that it is indeed compounds with 
growth regulating effects in the extract causing a reduction in the root growth of test species. The osmotic potentials of the stem extracts were measured with a Roebling digital micro-osmometer. Osmotic potential was calculated as described by Masterton et al. (1987).

\section{Isolation of 3,4-dihydroxybenzoic acid}

Fresh stems (100 g) of $P$. cynaroides were homogenized in 70\% aqueous acetone for $6 \mathrm{~h}$. The extraction solution was then placed into a flask and dried under vacuum by using a rotary evaporator (BUCHI ${ }^{\circledR}$ Rotavapor R-114) and a waterbath (BUCHI ${ }^{\circledR}$ Waterbath B480). The extract ( $2995 \mathrm{mg}$ ) was dissolved in water and submitted to a Diaion HP 20 chromatographic column $(2.5 \mathrm{~cm}$ i.d. $\times 29 \mathrm{~cm}$ length $)$. Elution was performed in a stepwise gradient of water:MeOH (100:0, 90:10, 80:20, 70:30, 60:40, 50:50. 40:60, 30:70, $20: 80,90: 10$ ), collecting 24 fractions of $100 \mathrm{ml}$ and monitoring them by UV spectrophotometry (Pharmacia LKB Ultrospec III spectrophotometer) at $280 \mathrm{~nm}$. A chromatogram was built from this data and fractions that gave a chromatographic peak were pooled and concentrated in vacuum.

The combined fraction of the main peak was further fractionated. Peaks were separated by high performance flash chromatography (HPFC) on a Horizon High Performance Flash Chromatography system (Biotage, Inc., Charlottesville, VA), using a reversed phase (12+ M C18, Biotage) column with the solvent gradient program set from $5 \%$ to $45 \%$ methanol over 48 tubes ( $3 \mathrm{ml}$ per tube), and finally washing the column with $100 \%$ methanol. The fractions were spotted on a reversed phase thin layer chromatography (TLC) plate (RP-18 $\mathrm{F}_{254 \mathrm{~s}}, 10 \times 20 \mathrm{~cm}$, EM Science, Gibbstown, NJ) with developing solvent 20\% methanol : $80 \%$ water. Spots were detected by observing under UV at $254 \mathrm{~nm}$. Fractions with similar spots were combined into four semi-crude fractions: Fractions 1, 2, 3 and 4. Fraction 2 was further subjected to purification on RP-18 plate using developing solvent 15\% methanol:85\% water. Four bands were collected from the plate. From these four bands, the one that was in the largest quantity, named Compound 1 (9.4 mg), was subjected to high performance liquid chromatography (HPLC) to confirm 
its purity, after which it was analyzed in the nuclear magnetic resonance (NMR) and mass spectrophotometer (MS) for characterization.

NMR data: Compound 1 was dissolved in $0.5 \mathrm{ml}$ of $\mathrm{CD}_{3} \mathrm{OD}$. The ${ }^{1} \mathrm{H}-\mathrm{NMR}$ spectra was acquired on a $200 \mathrm{MHz}$ Varian Mercury PLUS spectrometer at 199.97 MHz.

MS data: The molecular mass of the compound was determined on a Shimadzu 2010EV spectrometer. For ionization, an atmospheric pressure chemical ionisation probe was used. The sample was dissolved in methanol and directly injected into the probe.

\section{Lettuce seed bioassay of 3,4-dihydroxybenzoic acid}

3,4-Dihydroxybenzoic acid was purchased from Merck ${ }^{\circledR}$. A dilution series of 3,4dihydroxybenzoic acid was prepared, ranging from 1 to $500 \mathrm{mg}^{-1}$ of distilled water. Lettuce (L. sativa) cv. 'Great Lakes' was used as test species. The experimental design and growth conditions were the same as described in the 'lettuce seed bioassay of stem extract' section above. A dose-response curve was generated from the data using the CARD program (Liu et al. 2003).

\section{In vitro bioassay of 3,4-dihydroxybenzoic acid on $\boldsymbol{P}$. cynaroides explants}

A concentration range similar to the one used in the bioassay above (Lettuce seed bioassay of 3,4-dihydroxybenzoic acid) was incorporated into Murashige and Skoog (MS) medium (Murashige and Skoog 1962) to determine the effect of 3,4dihydroxybenzoic acid on in vitro root growth of $P$. cynaroides seedlings. The MS medium consisted of sucrose $(3 \%), 3 \mathrm{~g}^{-1}$ Gelrite $^{\circledR}$ and the respective concentrations of 3,4-dihydroxybenzoic acid. The $\mathrm{pH}$ of the medium was adjusted to 5.7 before autoclaving. In order to determine whether 3,4-dihydroxybenzoic acid was degraded during the medium sterilization procedure (autoclaving), 3,4-dihydroxybenzoic acid was autoclaved and analyzed by HPLC.

Thirty-day old in vitro-germinated seedlings (sterilization and excision method described in $\mathrm{Wu}(2007))$ with radicles removed at the hypocotyl were placed in the growth medium containing the different concentrations of 3,4-dihydroxybenzoic acid. Twenty explants 
per treatment medium were used and were cultured in a growth chamber under a 12-h photoperiod illuminated with cool, white fluorescent lamps providing $60 \mu \mathrm{mol} \mathrm{m}^{-2} \mathrm{~s}^{-1}$ PAR. Temperature of the growth chamber was $25 \pm 2^{\circ} \mathrm{C}$.

\section{Analysis of phenolic compounds in $P$. cynaroides cuttings by HPLC}

Phenolic compound analyses were done on semi-hardwood stems taken from the motherplant, which were suitable to be used as cuttings, and on those that had been planted in the mistbed and rooted after 90 days and 120 days. Phenolic compounds were analyzed using an HPLC (Hewlett Packard Agilent 1100 series) with DAD detection (diode array detector, 280, 325, $340 \mathrm{~nm}$ ). A Luna 3u C-18 (Phenomenex ${ }^{\circledR}$ ) reverse phase column ( $250 \mathrm{~mm}$ by $4.6 \mathrm{~mm}$ ) was used. A gradient elution was performed with water ( $\mathrm{pH}$ 2.6 adjusted with $\mathrm{H}_{3} \mathrm{PO}_{4}$ ) and acetonitrile (ACN) as follows: 0 min, $7 \% \mathrm{ACN} ; 0-20 \mathrm{~min}$, $20 \%$ ACN; 20-28 min, 23\% ACN; 28-40 min, 27\%, ACN; 40-45 min, 29\%, ACN; 45$47 \mathrm{~min}, 33 \%$, ACN. The flow rate was $1 \mathrm{ml} \mathrm{min}^{-1}$, and the injection volume was $20 \mu 1$. Identification of the phenolic compounds was done by comparing their retention times and UV spectrum with those of standards (purchased from Sigma Chemical Company, USA), which included syringic, gallic, protocatechuic, $p$-hydroxybenzoic, vanillic, ferulic, caffeic, and chlorogenic acids. The amount of each identified compound was determined and expressed in $\mu \mathrm{g} \mathrm{mg}^{-1}$ of dry sample.

\section{Statistical analysis}

In the in vitro study on the effects of 3,4-dihydroxybenzoic acid on P. cynaroides explants' root length and root fresh mass, twenty uniform explants were used in each medium treatment. Tukey's Studentised test was used to compare treatment means. Statistical analyses were done using the SAS program (SAS Institute Inc. 1996).

\section{Results}

\section{Osmotic potential of stem extracts}

Results from the osmometer readings showed that the osmolalities of the aqueous stem extracts ranged from 0 to $11 \mathrm{mOsmol} \mathrm{kg}{ }^{-1}$. Data from experiments with polyethylene glycol (PEG-6000) solutions of increasing osmolality showed that no osmotic 
interference of lettuce seed germination or root growth occurred up to $53 \mathrm{mOsmol} \mathrm{kg}{ }^{-1}$ (Bothma 2002). Therefore, the results for the stem extract concentrations which were used in the lettuce seed bioassay are considered to be indicative of effects caused by growth regulators, and not distorted by osmotic effects.

\section{Bioassay of stem extract}

Results shown in Fig. 1 illustrate a typical dose-response curve where aqueous solutions prepared from the stem crude extracts were able to both stimulate and inhibit rooting, depending on the extract concentration. At lower concentrations (200-800 $\left.\mathrm{mg} \mathrm{l}^{-1}\right)$, lettuce root growth was stimulated, while at higher concentrations of between $1000 \mathrm{mg} \mathrm{l}^{-1}$ and $5000 \mathrm{mg} \mathrm{l}^{-1}$, reduction in root growth was observed. At the $400 \mathrm{mg}^{-1}$ concentration, stimulation of root growth was the highest, which was $28 \%$ higher than the control. Although total inhibition was not observed, strong root inhibition was evident at the highest concentration (5000 $\mathrm{mg}^{-1}$ ).

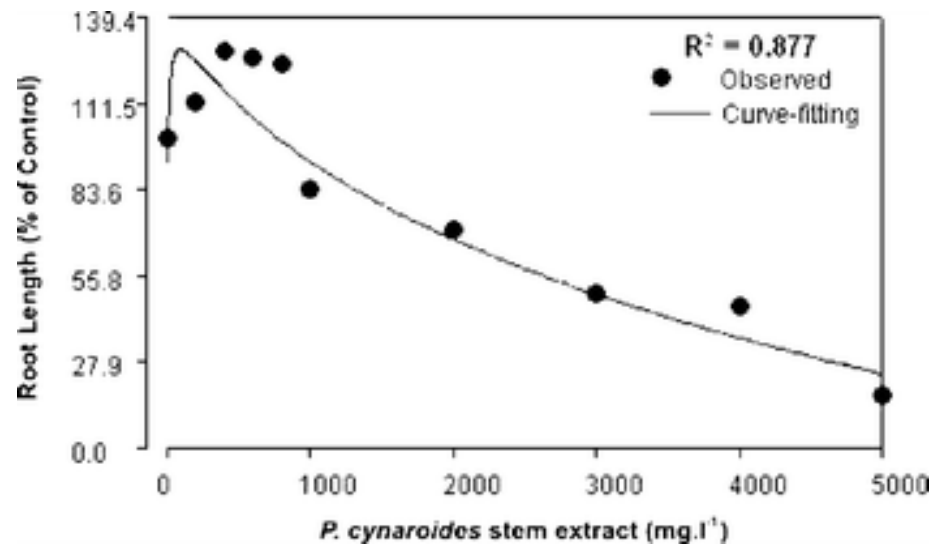

Fig. 1 Dose-response of $P$. cynaroides stem extract on the growth of lettuce seedlings

\section{Isolated compound}

Compound 1 was identified as 3,4-dihydroxybenzoic acid (Protocatechuic acid):

APCI-MS m/z: 153 [M-H] ; ${ }^{1} \mathrm{H}$ NMR (CD $\left.{ }_{3} \mathrm{OD}, 200 \mathrm{MHz}\right): 6.75$ (1H, d, J=8.0 Hz, H-5), $7.39(1 \mathrm{H}, \mathrm{dd}, J=2.0,8.0 \mathrm{~Hz}, \mathrm{H}-6), 7.43(1 \mathrm{H}, \mathrm{d}, J=2.0 \mathrm{~Hz}, \mathrm{H}-2)$. 
The chemical structure of 3,4-dihydroxybenzoic acid is shown in Fig. 2. Its identification was confirmed by comparing NMR and MS data with Sang et al. (2002), as well as with a reference standard. In total, twenty-eight fractions were isolated, of which the majority was found in very small amounts. Furthermore, NMR data showed that several of these fractions contained compounds which were similar in structure and were derivatives of 3,4-dihydroxybenzoic acid, indicating that phenolics found in the stems of $P$. cynaroides are made up mostly of 3,4-dihydroxybenzoic acid and related compounds.

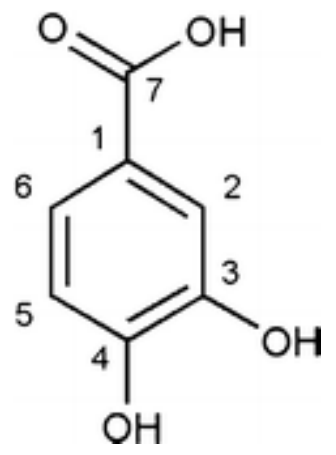

Fig. 2 Chemical structure of 3,4-dihydroxybenzoic acid

\section{Bioassay of 3,4-dihydroxybenzoic acid}

Figure 3 illustrates the response of lettuce root growth to a concentration series of 3,4dihydroxybenzoic acid. The effects of 3,4-dihydroxybenzoic acid on the lettuce root growth showed root growth stimulation at low concentrations and inhibition at high concentrations. The highest stimulation was at $100 \mathrm{mg} \mathrm{l}^{-1}$, where the mean root length was $23 \%$ longer than that of the control. The $\mathrm{ED}_{50}$ value of 3,4-dihydroxybenzoic acid for lettuce, which was calculated from the CARD program (dose-response curve), was $339 \mathrm{mg}^{-1}$. The sharp drop in the dose-response curve from the concentration of $200 \mathrm{mg} \mathrm{l}^{-1}$ onwards indicates the contrasting activity of root stimulation and inhibition within a relatively narrow concentration range of between $100 \mathrm{mg}^{-1}$ and $200 \mathrm{mg}^{-1}$ (Fig. 3). 


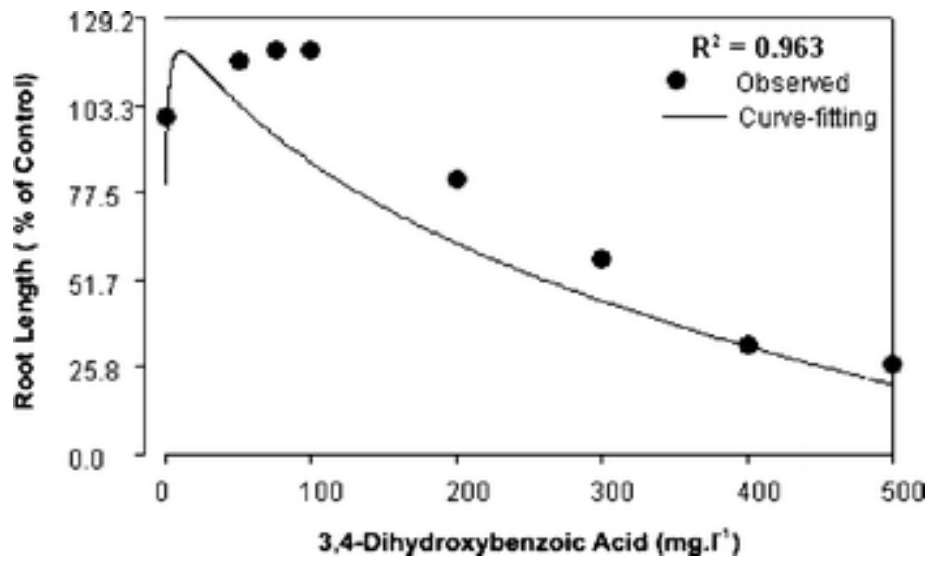

Fig. 3 Dose-response of 3,4-dihydroxybenzoic acid on the growth of lettuce seedlings

\section{Effects of 3,4-dihydroxybenzoic acid on $P$. cynaroides in vitro}

Results from the HPLC analysis showed that the concentration of 3,4-dihydroxybenzoic acid remained unchanged after autoclaving, which indicated that the compound was not affected by autoclaving. Table 1 shows the effects of 3,4-dihydroxybenzoic acid on the rooting of rootless seedlings after 3 weeks in culture. The response of the explants to 3,4dihydroxybenzoic acid at the lower concentration range between $1 \mathrm{mg} \mathrm{l}^{-1}$ and $50 \mathrm{mg}^{-1}$ is noteworthy in that non-observable effects were obtained, i.e., root growth was similar to the control in terms of mean root length and root mass. However, an increase in mean root length and root mass was noticeable from $75 \mathrm{mg} \mathrm{l}^{-1}$, even though the mean root length and root mass was not significantly higher (Table 1). Roots which formed on explants cultured on medium supplemented with $75 \mathrm{mg}^{-1}$ and $100 \mathrm{mg}^{-1}$ of 3,4dihydroxybenzoic acid, were visibly thicker and fleshier. This was particularly evident at the $100 \mathrm{mg}^{-1}$ concentration, which coupled with longer roots, resulted in significantly higher mean root mass. 
Table 1 Response of $P$. cynaroides explants to a series of 3,4-dihydroxybenzoic acid concentrations on MS medium cultured in vitro (After 3 weeks in culture)

\begin{tabular}{|c|c|c|}
\hline $\begin{array}{l}\text { MS medium + 3,4-dihydroxybenzoic } \\
\text { acid }\left(\mathrm{mg} \mathrm{l}^{-1}\right)\end{array}$ & $\begin{array}{l}\text { Mean root length } \\
(\mathrm{mm})\end{array}$ & $\begin{array}{l}\text { Mean root fresh mass } \\
(\mathrm{mg})\end{array}$ \\
\hline 0 & $5.50 \pm 0.93 \mathrm{ab}$ & $0.55 \pm 0.17 b$ \\
\hline 1 & $5.25 \pm 0.46 \mathrm{ab}$ & $0.58 \pm 0.15 b$ \\
\hline 5 & $5.00 \pm 0.00 \mathrm{ab}$ & $0.50 \pm 0.06 b$ \\
\hline 25 & $5.00 \pm 0.00 \mathrm{ab}$ & $0.55 \pm 0.07 b$ \\
\hline 50 & $5.30 \pm 0.52 \mathrm{ab}$ & $0.57 \pm 0.08 b$ \\
\hline 75 & $5.75 \pm 0.50 \mathrm{ab}$ & $0.88 \pm 0.15 b$ \\
\hline 100 & $7.76 \pm 2.79 \mathrm{a}$ & $2.66 \pm 1.40 \mathrm{a}$ \\
\hline 500 & $3.00 \pm 0.00 \mathrm{~b}$ & $0.30 \pm 0.00 \mathrm{~b}$ \\
\hline
\end{tabular}

Means in each column followed by different letters are significantly different at $P=0.05$ according to Tukey's studentised test

Coincidentally, at the concentration level in which root growth was stimulated (100 $\mathrm{mg}^{-1}$ ), root stimulation was also observed in the lettuce bioassay. Although a few explants produced roots in the medium containing the highest concentration $\left(500 \mathrm{mg}^{-1}\right)$ of 3,4-dihydroxybenzoic acid, it was clear that the concentration was toxic to the explants. Rapid browning of cut surfaces of the explants was observed immediately after planting, which soon spread to other parts of the explant. This browning effect is also often seen when explants containing high phenol contents are cultured in vitro, where large amounts of phenols are leached from the explants and inhibit the formation of roots and ultimately causes the death of the explant (Debergh and Read 1991; George 1996).

\section{Analysis of phenolic compounds by HPLC}

From the HPLC analysis, 3,4-dihydroxybenzoic, caffeic, ferulic, gallic and salicylic acids were identified (Fig. 4). In the stems taken from the motherplant, 3,4-dihydroxybenzoic 
acid $\left(12 \mu \mathrm{g} \mathrm{g}^{-1}\right)$, caffeic acid $\left(11 \mu \mathrm{g} \mathrm{g}^{-1}\right)$ and salicylic acid $\left(32 \mu \mathrm{g} \mathrm{g}^{-1}\right)$ were found in relatively low amounts, while traces of ferulic and gallic acids were also detected. However, in the analyses of the basal end of cuttings taken from the mistbed when rooting began (after 90 days), high quantities of 3,4-dihydroxybenzoic acid was found $\left(180 \mu \mathrm{g} \mathrm{g}^{-1}\right)$, which remained at a similar level after 120 days $\left(188 \mu \mathrm{g} \mathrm{g}^{-1}\right)$ (Fig. 4). At the same time period, the levels of caffeic acid $\left(29 \mu \mathrm{g} \mathrm{g}^{-1}\right)$ and salicylic acid $\left(17 \mu \mathrm{g} \mathrm{g}^{-1}\right)$ remained low. 


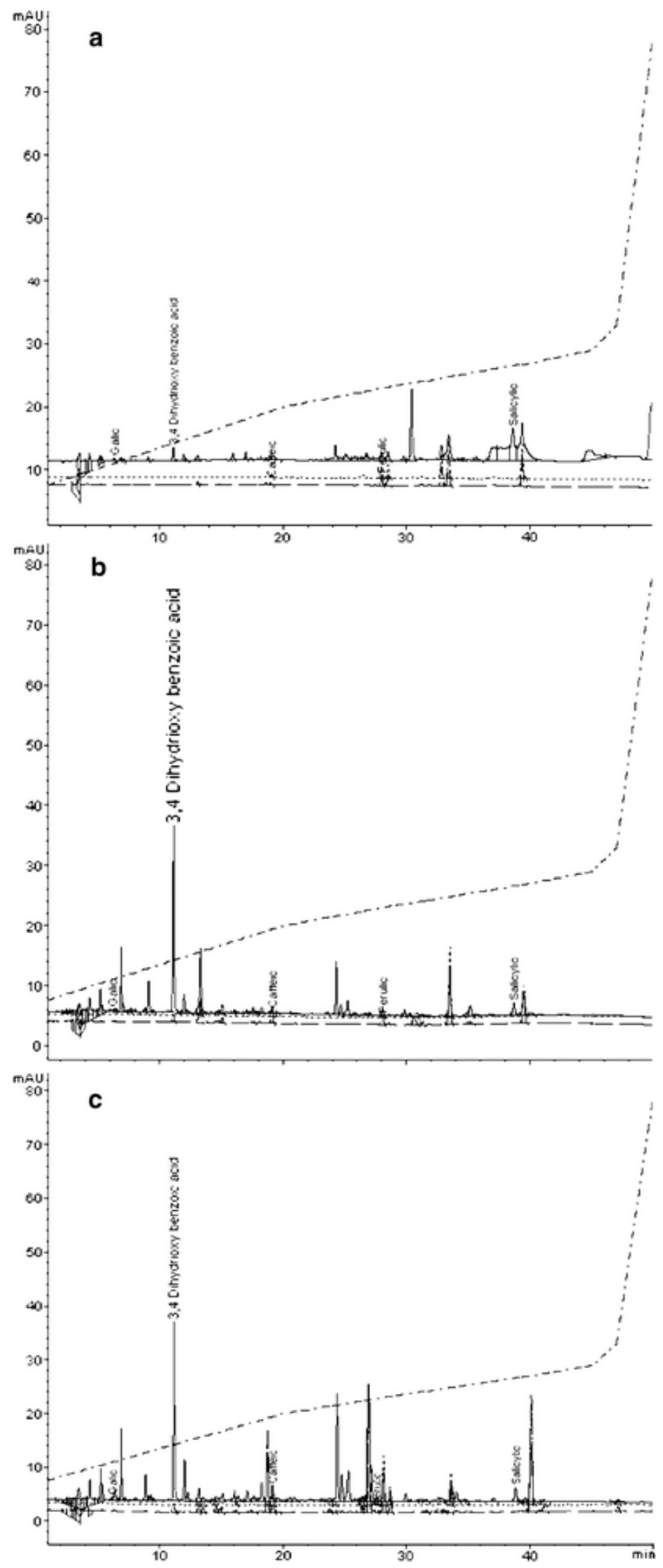


Fig. 4 HPLC analysis of the basal end of stems. (A) Stems taken from motherplant; (B) After 90 days in mistbed when rooting was observed; (C) After 120 days when root growth was high

Furthermore, from the results of the in vitro propagation investigation and the quantitative analysis, a relationship between the concentration levels of 3,4dihydroxybenzoic acid and root formation can be made. The concentration level $\left(100 \mathrm{mg} \mathrm{l}^{-1}=100 \mathrm{ppm}\right)$ of 3,4-dihydroxybenzoic acid at which root stimulation of the $P$. cynaroides explants was observed, corresponded with the amount of 3,4-

dihydroxybenzoic acid $\left(180 \mu \mathrm{g} \mathrm{g}^{-1}=180 \mathrm{ppm}\right)$ found in the stem cuttings during rooting in the mistbed. It can therefore be deduced that once the concentration level of 3,4dihydroxybenzoic acid in cuttings reached $100 \mathrm{mg} \mathrm{l}^{-1}$ or more, root formation was stimulated. In the in vitro propagation study, although the exact concentration between $100 \mathrm{mg}^{-1}$ and $500 \mathrm{mg} \mathrm{l}^{-1}$ where root stimulation would have ceased and inhibition commenced is not known, nevertheless, from the results for cuttings in the mistbed, it can be assumed that up to at least $180 \mathrm{mg}^{-1}$, root formation would still be stimulated.

\section{Discussion}

3,4-Dihydroxybenzoic acid is a common and widespread allelopathic agent that is able to influence growth at various stages of plant development (Rice 1984). 3,4-

Dihydroxybenzoic acid and other phenolic compounds have also been isolated from plant species such as Arctostaphylos glandulosa (Chou and Muller 1972), Chrysanthemum morifolium (Kil and Lee 1987), Pennisetum clandestinum and Cunninghamia lanceolata (Chou et al. 1987), Rumex japonicus (Elzaawely et al. 2005) and Vulpia myuros (An et al. 2000). Bioassays of phenolics in these reports showed root inhibition. In addition, other chemically-related compounds such as 2,5-dihydroxybenzoic acid have also been reported to affect the rooting of Tilia americana (Morsink and Smith 1975). Furthermore, from the report by Bär et al. (1997), 3,4-dihydroxybenzoic acid extracted from three Kalanchoe spp. had non-observable effects at lower concentrations on the root growth of Kalanchoe cuttings, while root growth was inhibited at higher levels. 
With regard to $\mathrm{ED}_{50}$ value, it is known that differences in the sensitivity of receiving plant species are key factors to the inherent phytotoxicity of allelochemicals (Einhellig 2004). No research paper could be found that reports on the $\mathrm{ED}_{50}$ value of 3,4dihydroxybenzoic acid on lettuce seeds. However, dose-response bioassays of other phytotoxins revealed that lettuce was less sensitive than other test species. For instance, with parthenin, the $\mathrm{ED}_{50}$ value for lettuce roots was four times higher than the dose level necessary to give the same response on the most sensitive species Ageratum conyzoides (Belz et al. 2007). Thus, the effective concentration of 3,4-dihydroxybenzoic acid can be even more clearly shown when test species of different sensitivities are used. Further studies in this regard are necessary to allow comparisons between the effective dosages of 3,4-dihydroxybenzoic acid and other phytotoxins.

Results from the in vitro study illustrated the effects of 3,4-dihydroxybenzoic acid on the root growth of plant species. No observable effects on the rooting of $P$. cynaroides were found at the lower concentrations, while stimulation of root growth was apparent when the concentration reached $100 \mathrm{mg}^{-1}$. Although the exact concentration range of root stimulation is not known, it is clear that at $500 \mathrm{mg}^{-1}, 3,4$-dihydroxybenzoic acid was toxic to the P. cynaroides explants, which was demonstrated by root inhibition and browning of explants. Few studies have used in vitro conditions to determine the effects of plant-extracted phenolics on root growth. Nevertheless, Mucciarelli et al. (2000) reported that root growth of Nicotiana tabacum explants, which were cultured on MS medium containing 3,4-dihydroxybenzoic acid, was also stimulated at low concentrations, while root inhibition was observed at the higher concentration level.

Considerable differences in the level of 3,4-dihydroxybenzoic acid were found between stems taken from the motherplant and the basal ends of rooted cuttings in the mistbed after 90 days and 120 days. This indicated that the endogenous levels of 3,4dihydroxybenzoic acid of the cuttings increased after they were planted, and that this high level was maintained during the rooting period. Although no reports have shown changes of 3,4-dihydroxybenzoic acid during rooting of cuttings, Pellissier (1994) reported that root formation was stimulated by higher concentrations of 3,4-dihydroxybenzoic acid in 
Picea abies. Furthermore, while the phenolic compound coumarin, which has been reported to regulate rooting (San Antonio 1952; Dhawan and Nanda 1982) was not detected in the stems of $P$. cynaroides, the presence of other phenolic compounds such as caffeic, ferulic, gallic and salicylic acids, which were detected by HPLC analysis, is noteworthy. It is likely that the presence of these phenolics in the cuttings played a role in promoting rooting, since numerous research papers have also identified caffeic, ferulic and gallic acids together with 3,4-dihydroxybenzoic acid in plants such as C. lanceolata (Zhiqun et al. 2002), Phytolacca spp. (Kim et al. 2005) and R. japonicus (Elzaawely et al. 2005). In addition, in the C. lanceolata extracts, which contained 3,4-dihydrixybenzoic acid, ferulic acid and gallic acid, stimulation of root growth of test species at high concentrations was observed (Zhiqun et al. 2002). Moreover, salicylic acid was also found to be stimulatory to root initiation of Phaseolus aureus cuttings (Kling and Meyer 1983). It can therefore be assumed that this group of phenolic compounds has an important role to play in regulating root formation, particularly in terms of stimulation. It is well known that several compounds usually act together in controlling many functions of a plant, including root formation. In this regard, further investigations is needed to study a possible relationship between 3,4-dihydroxybenzoic acid and plant hormones such as indole-3-acetic acid. However, from this study, based on the relatively large amounts of 3,4-dihydroxybenzoic acid found in the stem extract, and on the stimulatory effects on root growth in $P$. cynaroides explants in vitro, as well as on the high endogenous levels of the compound in cuttings during rooting in the mistbed, it is proposed that 3,4-dihydroxybenzoic acid could play a primary role in root formation, depending largely on its endogenous concentration. The results of this study provide a better understanding of how phenolic compounds might affect the rooting of $P$. cynaroides cuttings.

\section{References}

An M, Haig T, Pratley JE (2000) Phytotoxicity of Vulpia residues: II. Separation, identification, and quantification of allelochemicals from Vulpia myuros. J Chem Ecol 26(6):1465-1476. 
Bär W, Pfeifer P, Dettner K (1997) Intra- and inter-specific Allelochemical effects in three Kalanchoe-species (Crassulaceae). J Biosciences 52(7-8):441-449.

Belz RG, Reinhardt CF, Foxcroft LC, Hurle K (2007) Residue allelopathy in Parthenium hysterophorus L. - does parthenin have a leading part? Crop Protection 26(3):237-245.

Biran I, Halevy AH (1973) Endogenous levels of growth regulators and their relationship to the rooting of dahlia cuttings. Physiol Plant 28:244-247.

Bothma A (2002) Allelopathic potential of silverleaf nightshade. (Solanum elaeagnifolium Cav.). MSc Thesis. Department of Plant Production and Soil Science, University of Pretoria, Pretoria, South Africa.

Chou C-H, Hwang S-Y, Peng C-I (1987) The selective allelopathic interaction of a pasture-forest intercropping in Taiwan. Plant Soil 98:31-41.

Chou C-H, Muller CH (1972) Allelopathic mechanisms of Arctostaphylos glandulosa var. zacaensis. Am Midl Nat 88(2):324-347.

Debergh PJ, Read PJ (1991) Micropropagation. In: Debergh PC, Zimmerman RH (eds) Micropropagation: Technology and application. Dordrecht Kluwer Academic Publishers, pp $1-14$.

Dhawan RS, Nanda KK (1982) Stimulation of root formation on Impatiens balsamina L. cuttings by coumarin and the associated biochemical changes. Biologia Plant 24(3):177182.

Einhellig FA (2004) Mode of allelochemical action of phenolic compounds. In: Macías FA, Galindo JCG, Molinillo JMG, Cutler HG (eds) Allelopathy: Chemistry and mode of action of allelochemicals. CRC Press. 
Elzaawely AA, Xuan TD, Tawata S (2005) Allelopathic activity and identification of allelochemicals from Rumex japonicus Houtt. Allelopathy J 16(2):209-216.

Fadl MS, Hartmann HT (1967) Relationship between seasonal changes in endogenous promoter and inhibitors in pear buds and cutting bases and the rooting of pear hardwood cuttings. Proc Am Soc Hort Sci 91:96-112.

George EF (1996) Plant propagation by tissue culture. Part 2: In Practice, 2nd edn. Exegetics Ltd. Edington, Wilts. BA13 4QG, England, pp 639-651.

Hackett WP (1970) The influence of auxin, catechol and methanolic tissue extracts on root initiation in aseptically cultured shoot apices of the juvenile and adult forms of Hedera helix. J Am Soc Hort Sci 95:398-402.

Hammerschlag F (1982) Factors influencing in vitro multiplication and rooting of the plum rootstock 'Myrobalan' (Prunus cerasifera Ehrh.). Journal of the American Society for Horticultural Science 107:44-47.

James DJ, Thurbon IJ (1981) Shoot and root initiation in vitro in the apple rootstock M9 and the promotive effects of phloroglucinol. J Hort Sci 56:15-20.

Jones OP, Hatfield SGS (1976) Root initiation in apple shoots cultured in vitro with auxins and phenolic compounds. J Hort Sci 51:495-499.

Kil B-S, Lee SY (1987) Allelopathic effects of Chyrsanthemum morifolium on germination and growth of several herbaceous plants. J Chem Ecol 13(2):299-308.

Kim YO, Johnson JD, Lee EJ (2005) Phytotoxicity effects and chemical analysis of leaf extracts from three Phytolaccaceae species in South Korea. J Chem Ecol 31(5):11751186. 
Kling GJ, Meyer MM Jr (1983) Effects of phenolic compounds and indoleacetic acid on adventitious root initiation in cuttings of Phaseolus aureus, Acer saccharinum, and Acer griseum. HortScience 18(3):352-354.

Liu DL, An M, Johnson IR, Lovett JV (2003) Mathematical modelling of allelopathy. III. A model for curve-fitting allelochemical dose responses. Nonlinearity Biol Toxicol Med $1(1): 37-50$.

Masterton WL, Slowinski EJ, Stanitski CL (1987) Chemical principles. 6th edn. HoltSaunders International, pp 360-364

Morsink WAG, Smith VG (1975) The effect of some monohydrobenzoic and dihydrobenzoic acids as auxin synergists on rooting softwood cuttings of basswood (Tilia americana) under mist. Can J Forest Res 5:500-502.

Mucciarelli M, Scannerini S, Gallino M, Maffei M (2000) Effects of 3,4dihydroxybenzoic acid on tobacco (Nicotiana tabacum L.) cultured in vitro. Growth regulation in callus and organ cultures. Plant Biosyst 134(2):185-192.

Murashige T, Skoog F (1962) A revised medium for rapid growth and bio assays with tobacco tissue cultures. Physiol Plant 15:473-497.

Pellissier F (1994) Effect of phenolic compounds in humus on the natural regeneration of spruce. Phytochemistry 36(4):865-867.

Perold WG, Beylis P, Howard AS (1973) Metabolites of Proteaceae. Part VII. The occurrence of $(+)$-D-allose in nature: Rubropilosin and pilorubrosin from Protea rubropilosa Beard. J Chem Soc Perkin Trans I:643-649. 
Reuveni O, Adato I (1974) Endogenous carbohydrates, root promoters and root inhibitors in easy- and difficult-to-root date palm. (Phoenix dactylifera L.) offshoots. J Am Soc Hort Sci 99:361-363.

Rice EL (1984) Allelopathy. Academic Press, Orlando, pp 272-274.

Richards M (1964) Root formation on cuttings of Camellia reticulate var. 'Capt. Rawes'. Nature 204:601-602.

San Antonio JP (1952) The role of coumarin in the growth of roots of Melilotus alba. Bot Gaz 114:79-95.

Sang S, Lapsley K, Jeong W-S, Lachance PA, Ho C-T, Rosen RT (2002) Antioxidative phenolic compounds islated from almond skins (Prunus amygdalus Batsch). J Agric Food Chem 50:2459-2463.

SAS Institute Inc (1996) The SAS system for Windows. SAS Institute Inc. SAS Campus drive, Cary, North Carolina, USA.

Still SM, Dirr MA, Gartner JB (1976) Phytotoxic effects of several bark extracts on mung bean and cucumber growth. J Am Soc Hort Sci 101:34-37.

Taylor GG, Odom RE (1970) Some biochemical compounds associated with rooting of Carya illinoensis stem cuttings. J Am Soc Hort Sci 95:146-151.

Verotta L, Orsini F, Pelizzoni F, Torri G, Rogers CB (1999) Polyphenolic glycosides from African Proteacae. J Nat Prod 62:1526-1531.

Wu HC (2006) Improving in vitro propagation of Protea cynaroides L. (King Protea) and the roles of starch and phenolic compounds in the rooting of cuttings. $\mathrm{PhD}$ thesis. University of Pretoria, Pretoria. 
Wu HC, Du Toit ES, Reinhardt CF (2007) Micrografting of Protea cynaroides. Plant Cell Tiss Org Cult 89(1):23-28.

Zhiqun H, Haig T, Silong W, Sijie H (2002) Autotoxicity of Chinese fir on seed germination and seedling growth. Allelopathy J 9(2):187-193.

Zimmerman RH (1984) Rooting apple cultivars in vitro: Interactions among light, temperature, phloroglucinol and auxin. Plant Cell Tiss Org Cult 3:301-311. 